Canadian Journal of Higher Education Revue canadienne d'enseignement supérieur Volume 46, No. 3, 2016, pages i-v

\title{
Introduction to the Special Issue on Governance in Higher Education
}

Anne C. Charles

Conestoga College Institute of Technology and Advanced Learning

The genesis of this special issue on governance in higher education was an inquiry from a member of the Canadian Society for the Society of Higher Education (CSSHE). Simply put, the member asked: What can CSSHE do to foster interest into the theory and practice of governance in Canadian higher education? Good question!

CSSHE was founded in 1970 with a mandate to provide a means of communication among persons conducting or using research in postsecondary education and to promote scholarship through publications and conferences. The member's question was timely. Just a few weeks later at the CSSHE 2012 annual conference an informal meeting was held to gauge the level of interest within the membership in thinking about governance; the CSSHE Affinity Group on Governance and Leadership in Higher Education was formed shortly thereafter.

The collection of papers in this special issue describe a subfield of study within higher education, which is central but also interdisciplinary. Scholars of governance in higher education draw upon ideas, concepts, and theories that have been developed in other fields in order to understand a range of issues affecting our institutions and their relationships with stakeholders. The papers in this issue all examine aspects of the governance dilemma: a dilemma premised on the separation of oversight and practice but which is complicated by power and authority, values, interests, and participation. As the papers demonstrate, governance operations may appear to be delineated in principle, but they are complicated by government, institutions, policies, and relationships. Furthermore, the raison d'être of higher education - the pursuit and dissemination of knowledge, teaching and learning, and service to the community - has led to the development of unique institutional structures and governance frameworks that separate the fiduciary from the academic, while prizing stakeholder engagement and participation in academic decision-making.

The papers represent a sample of the exemplary research and scholarship being conducted in Canada. Constitutional arrangements in this country have made higher education a provincial governmental responsibility, but it is a national concern. Regional, eco- 
nomic, social, and cultural differences may have influenced the development of provincial institutional arrangements, but there are shared concerns and challenges. The seven papers provide examples of governance issues in higher education and show some of the different challenges at the macro, meso, and micro levels. They cover a range of topics that are project-specific but have broader implications for other jurisdictions, institutions, policy, and practice. Each introduces a new angle and/or conceptual combinations on themes of governance. They describe the complexity of this field of study and show how the dynamic activity of stakeholders' participation takes place within highly politicized environments.

The first two papers discuss aspects of governance at a system (macro) level. Ontario is Canada's most populated province, with more higher education institutions than any other province in the country. Although technically still a binary higher education system, the boundaries between universities and colleges have become more blurred in recent years, especially by policies designed to promote accessibility. At the time of writing, Ontario has 20 public universities, 24 colleges in the Ontario Colleges of Applied Arts and Technology system, and a private, career-college sector.

In their paper, "Institutional Diversity in Ontario's University Sector: A Policy Debate Analysis," Pierre Piché and Glen A. Jones look at institutional diversity in Ontario's university system. They share the findings of a qualitative research study in which they examined documents and collected data from semi-structured interviews. With a view to extending our understanding of the discussion regarding the concept of diversity, they describe a system of higher education in Ontario in which, despite many reports and reviews over several decades, stakeholders have failed to reach a point of consensus to facilitate policy implementation.

Piché and Jones examine the contemporary policy analysis debate, describing how stakeholders share fundamental values about diversity in principle and show where divided interests lead to different interpretations of the concept in practice. They explain that confusion also extends to diversity's companion but not interchangeable concept - differentiation. Illustrating how interests have trumped values, extended debate, and slowed policy implementation, they discuss the broad policy goals of accessibility, quality, and accountability. They point to two different instrumental policy approaches available to the Ontario government that would increase system diversity:

- through the creation of new institutional types, or

- through the use of financial levers, incentive funding, performance funding, and strategic mandate agreements.

Piché and Jones argue that the contemporary policy debate in Ontario has now moved to focus on the latter pathway as a way to motivate institutional behaviour.

The second paper in this issue also discusses governance at the system level. Catherine Larouche, Denis Savard, Lucie Héon, and Jean-Joseph Moisset in the paper entitled "Analyse typologique des plans stratégiques des universities québécoises" provide insight into governance in higher education in Québec. They discuss the challenges for evaluating the policy performance of universities within a differentiated and diversified provincial higher education system. The authors share their findings derived from an empirical study in which they investigated and analyzed strategic plans of 17 universities in Québec for content. Explaining that strategic planning is part of a results-based management 
approach, they draw readers' attention to the requirement in Québec for universities to periodically reflect on their mission and vision, identify goals and priorities, and specify objectives towards achievement. Larouche, Savard, Héon, and Moisset describe performance evaluation as a governance dilemma. The authors explain that while in principle there is general agreement on the need for accountability, the conflicting goals resulting from the triple core mission of universities (teaching, research, and community service) and the values from within the academy (autonomy and academic freedom) complicate the exercise of performance evaluation.

In a university system that is differentiated and diversified, the authors argue that a "one size fits all" model for performance evaluation does not suffice. They offer a means to move forward through the application of a typological approach. They showcase a typological model of institutional types that classifies universities on the basis of values and principles, system governance, strategies, education, and research. These criteria result in the identification of seven institutional designs: academic, public service, market, entrepreneurial, political, living environment, and learning. They demonstrate that application of this typological model can be used for performance evaluation, as it is able to reflect multiple aspects of diversity within the system.

Daniel W. Lang's paper, "Five Case Studies of Governance in Tertiary Education," examines governance in five small, public, not-for-profit tertiary institutions. He applies three empirical tests to discover what the boards look like, how they perform, and the expectations and objectives. Drawing attention to the "principal-agent dilemma" in which public funds are transferred to higher education institutions in exchange for services provided, Lang illustrates how common assumptions about the boundaries of oversight versus management can become blurred. His findings show a tendency in small, specialized institutions to move toward a working-board model. While this model may be attractive for financially challenged institutions, the less clearly delineated lines of demarcation between governance and management pose a challenge for practice. Crossing of boundary lines, he argues, can promote or hinder performance and can either serve or circumvent accountability.

Linda Muzzin challenges readers to review assumptions about governance. In her paper, "Theorizing College Governance across Epistemic Differences: Awareness Contexts of College Administrators and Faculty," she offers insight into how things work in Canada's community colleges. Using a symbolic interactionist lens (sociology) informed by a framework of interpretation, Muzzin describes how the practice of governance in colleges is shaped by socially constructed meanings. The goal of Muzzin's study was to map the articulation and experiences by describing interactions between faculty and administrators. Through extensive in-depth interview research, Muzzin documents some of the everyday working experiences of hundreds of faculty and administrative staff in Canada's colleges.

Muzzin argues that we need to think differently about how governance is theorized. Reality, she explains is particular, norms are not shared, and openness and transparency should not be presumed as a given. Muzzin illustrates that everyday realities in Canada's community colleges are not, in fact, common, and that the social construction of everyday realities affects the interaction between faculty and administrative staff (epistemic community groups), each of whom have different awareness contexts. She draws our attention to a deep ontological and epistemological divide that impacts the practice of governance. Muzzin's work demonstrates that there is no singularity of awareness and that context 
is important. Her work points to a selective lack of transparency and reluctance to share information, aspects that affect the performance of governance. She describes how some interaction takes place within a closed awareness context, whereas other interactions take place in mutual suspicion, mutual pretence, or open awareness contexts. Muzzin offers a new theoretical lens through which the practice of governance in Canada's community colleges can be viewed.

Academic senates in Canada's universities is the subject of Lea Pennock, Glen A. Jones, Jeff M. Leclerc and Sharon X. Li's paper, entitled "Challenges and Opportunities for Collegial Governance at Canadian Universities: Reflections on a Survey of Academic Senates." The team provides insight into the effectiveness of senates with respect to the mandated role of academic decision-making vis-à-vis actual practice. They share findings of a research project where senators were surveyed and asked open-ended questions about their work, level of engagement, perceived role, and perceptions of effectiveness.

The findings point to a deficit, or tension, in terms of a senate's oversight role versus goal attainment and lead us to question whether collegiality and effective oversight are mutually exclusive or whether they can coexist. Respondents, who included faculty, administrative officers, students, and staff, point to tensions within the senate that impact the practice of governance. Personal agendas were perceived as a barrier to effectiveness. Feelings of disengagement and lack of commitment were described. Doubts were expressed about the capacity to meaningfully participate in the process of governance, and miscommunication and lack of communication were said to exacerbate the dysfunctional dynamics. Academic role demands (teaching, promotion, and tenure) and governance duties (which were said to unequally impact junior faculty) were also said to conflict, leading to the practice of surrendering some governance responsibilities to academic managers with the senate, in effect, rubber stamping decisions. The authors argue there is a growing awareness of the need to improve senate effectiveness, and they offer suggestions to improve functioning, build respect, and improve capacity.

The call to make governance institutions more effective is echoed by Patrick Lougheed and Michelle Pidgeon. In their paper, "Exploring Effective Academic Governance at a Canadian University," they share the findings of a study focused on an academic senate. They interviewed current and past-serving members of the senate, with a view to discovering their views on effectiveness of governance in their institution. They were told that senators had concerns with committees, membership, and dialogue and deliberation. The findings raise important questions for scholars and practitioners. The functioning of bicameral governance is premised on the separation of academic and fiduciary oversight roles, but as the findings indicate, the practice of academic governance can become more procedural than substantive over time. This has important implications for the senate as a functional form of governance in Canadian universities and raises questions about how institutional processes facilitate or inhibit participation in academic governance and decision-making.

The final paper in this issue showcases a case study of positive action. It shows what can be achieved when there is willingness to work toward a common goal. Margo Baptista's paper entitled "A Unique Governance Learning Experience: Acquiring and Transferring Knowledge on the Topic of Presidential Search" shows how board development exercises can contribute to the practice of governance. Boards of Governors in higher education 
institutions act as agents of the provincial government and have fiduciary responsibilities that include policy, strategic planning and oversight, and audit. Baptista describes the experience of Grant MacEwan University's Board of Governors who engaged in an action research exercise to develop the requisite knowledge and skills for their office and attendant responsibilities. Focusing on the process of presidential search and informed by knowledge management theory, Baptista describes how knowledge acquisition and transfer strategies can be used to deepen the understanding of the roles and responsibilities of governance. Baptista's work also showcases the benefits of using action learning to build intellectual capital and enhance board effectiveness, demonstrating how positive action can enhance member engagement and build institutional memory.

To summarize, these papers highlight some of the fundamental contemporary challenges and issues facing governance in higher education in Canada today. The papers may be particular to a project of study, but the important themes and questions raised by the authors have broader implications for other jurisdictions, institutions, policy, and practice. Readers are challenged to examine assumptions of the separation of oversight and practice and to reflect on the principles of good governance and the means to ends. I anticipate that these papers will provide good reference material and will be used to inform further research on governance in higher education. It is also my great hope that this issue will foster more interest into the theory and practice of governance in higher education and promote engagement. I thank the authors, peer reviewers, CSSHE Board of Directors, and the editor and staff of CJHE for making this project possible. 